\title{
Effect of Sewing Parameters on Seam Strength and Seam Efficiency
}

\author{
Bhavesh Rajput ${ }^{1}$, Madhuri Kakde ${ }^{1 *}$, Sujit Gulhane ${ }^{1}$, Sudhir Mohite ${ }^{2}$ and Raichurkar PP ${ }^{1}$ \\ ${ }^{1}$ Mukesh Patel School of Technology Management and Engineering, Narsee Monjee Institute of Management Studies (NMIMS), India \\ ${ }^{2}$ Division Head, Alok Industries Pvt. Ltd. Garment Division, India
}

*Corresponding author: Madhuri Kakde, Centre for Textile Functions, Mukesh Patel School of Technology Management and Engineering, Narsee Monjee Institute of Management Studies (NMIMS) Shirpur Campus Shirpur, Dhule, India

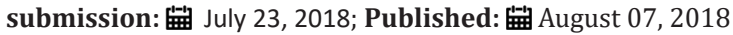

\begin{abstract}
Seam quality is determined by the correlation between types of fabric, structures of fabric, sewing threads and selection of stitches and seams The performance of seam also depends on the sewing conditions like size of needle, sewing thread tension, stitches per inch and lastly on the proper working and maintenance of the stitching machine. The objective of present study is to investigate and scrutinize the impact of weft knitted fabric structures, sewing thread types and stitch types on seam strength and efficiency of superimposed type of seam for cotton apparels. An experimental design was employed for the study which includes two types of sewing thread and four classes of stitch. The seam strength and efficiency of the fabric were determined by using the tensile testing machine. Seam strength have been measured and analyzed both in course and wales directions. The results revealed that differences existed between the two different thread in relation with seam strength and seam efficiency. Polyester-wrapped threads with a polyester filament core thread shows better seam strength and seam efficiency. This study also assists garment manufacturers to utilize suitable thread type and stitch type to reach quality seams to get to know customers' requirements in terms of seam.
\end{abstract}

Keywords: Seam; Stitch; Seam efficiency; Seam strength; Sewing thread; Seam quality

\section{Introduction}

The basic constituent of quality apparel is stitches and seams. The different components of apparel joint together by means of stitching operation and seams are responsible for giving the apparel shape for wear [1]. The overall performance of the apparel in use is mainly depends on the quality of seam [2]. Seam is the joining of two or more pieces of fabrics by means of stitching. The quality of seam greatly influences on the quality of apparel. The quality of Seam is assessed by means of its efficiency, elongation, bending, stiffness, abrasion resistance, seam slippage strength, puckering, tightness, boldness and seam damage [3]. A good seam having various functional and aesthetic requirements. The functional performance of the seam is evaluated by efficiency, elongation, density, slippage, bending stiffness and abrasion resistance of seam [4]. The basic raw material of garmenting is fabric and sewing thread. The apparel seam quality depends on raw material characteristics [5]. Seam performance by means of durability is based on the strength and efficiency of seam as well as seam appearance along the seam line attributed by the seam puckering [6]. These seam parameters are very important for garment manufacturers and customers, as it affects the customers' opinion regarding quality of garment [7]. Some of the manufacturers select stitch classes, stitch density and sewing threads without consideration to their influence on the overall performance of the apparel being made, resulting in failure of the seam during use [8]. It is therefore very important to select appropriate seam for better performance of apparel. Seam types is one of the factor influencing the overall performance of the seam in terms of durability, comfort, potential for alteration. The appearance of a seam is generally lead by the proper relationship between the size and type of thread, the stitch density and its types and the texture and weight of the fabric [9]. Many researchers found that fabric quality parameters like fabric density, fabric thickness, tensile strength, extensibility, bending rigidity and shear rigidity have extreme effect on quality of seam [10].

Poor seam performance makes the garment inappropriate even though the material strength is high. Therefore it is very crucial to divine the seam strength in terms of the performance of apparels during use [11]. It is defined as a load required for breaking seam and it results from the breakage of either textile material or sewing thread or sometimes both simultaneously. Seam strength is depends on the fabric quality, thread strength and stitch density along with the stitch and seam selection and sewing conditions. But it has been found that the fabric strength is not expected to cause any adverse effect on seam strength. Seam strength correlates with thread types, different classes of seam and stitch $[12,13]$. Many previous studies reported that seam strength is depends on the thread strength and stitch density. Stitch length is indirectly proportional 
to the seam strength. It is due to the fact that, as the stitch length increases, the number of loops that shares the load decreases, resulting in decreasing seam strength [14]. Seam strength of higher density fabric is found better than that of lower density [7]. A good sewing thread should have sufficient tensile strength, should be uniformly twisted throughout the length, smooth and elastic, and plied yarn treated by special finishes to increase its abrasion resistance during stitching operation and can be spun from staple yarn, filament or core spun yarns. The thread must be withstand the several wash and hold the seams together for the life of the garment [13]. Higher strength of thread is prone for giving higher seam strength shows better functional performance of seam [15]. The other parameters of sewing thread also decide the seam performance such as type of sewing thread, number of ply, type of finish, twist and size of thread $[1,6]$. Apparel seam performance is depends on the fabric cover factor, fabric weight, thickness, tensile strength, fabric shrinkage along the fabric length and width, resiliency, bending rigidity, flexural rigidity and shear rigidity [16]. Many researchers have been studied on fabric sewability of various types of fabrics. Research studies revealed that both stitch length and stitch density together with knitted fabric relaxation methods has found significant influence on seam elongation $[13,17]$.

\section{Material and Method}

\section{Material}

The analysis of seam quality was carried out on three types of weft knitted cotton fabrics of different constructions. The structures of the knitted fabric were plain single jersey, plain $1 \times 1$ rib double jersey and plain interlock double jersey. The characteristics of these fabrics are shown in Table 1.

Table 1: Fabric specifications.

\begin{tabular}{|c|c|c|c|}
\hline Properties & Singe Jersey & Rib & Interlock \\
\hline Yarn linear density (Ne) & 30 & 30 & 30 \\
\hline Wales per inch (WPI) & 28 & 26 & 30 \\
\hline Courses per inch (CPI) & 58 & 45 & 1170 \\
\hline Stitch density & 1624 & 1170 & 1.66 \\
\hline Stitch length (mm) & 2.40 & 2.55 & 235 \\
\hline Fabric GSM & 121 & 187 & 453.4 \\
\hline Bursting strength (kPa) & 242.3 & 250.3 & $1.0 \%$ \\
\hline Spirality (\%) & $3.0 \%$ & $1.0 \%$ & 12.2 \\
\hline Shrinkage $\%$ (course wise) & 5.1 & 13.3 & 13.7 \\
\hline
\end{tabular}

To measure fabric weight in terms of gram per square meter used GSM cutter and electronic weighing balance. The ASTM-D105911 methodology is used for fabric yarn count determinations. ASTM D3786-01 test method was used to measure the bursting strength single jersey, rib and interlock fabric. The two important characteristics for seam quality evaluation (seam efficiency, and seam strength) were inferred as critical dimensions for seam quality eval-

Table 2: Specifications of sewing threads. uation. Each selected fabric was sewn by different sewing threads. The twist per unit length of sewing thread was measured according to ASTM-D1423 and the tensile strength of sewing threads was performed at a gauge length of $250 \mathrm{~mm}$ on Zwick tensile testing machine at $35 \mathrm{~mm} / \mathrm{minute}$ as per ASTM-D2256. The specifications of the sewing threads are shown in Table 2.

\begin{tabular}{|c|c|c|c|}
\hline Linear Density (Tex) & Twist Direction & Tenacity (CN/Tex) & Breaking Elongation (\%) \\
\hline 40 & Z/S & 43.89 & 25.07 \\
\hline 60 & Z/S & 54.09 & 27.00 \\
\hline 80 & Z/S & 60.97 & 28.67 \\
\hline
\end{tabular}

The suitable needle size was used in stitching works and the stitch density is kept constant at 14 stitches per inch. Fabrics were stitched on Juki lock stitch, overlock stitch \& flat lock stitch sewing machines at a speed of 4500 stitches/minute and produced superimposed seam. ASTM-D1683 methodology was used to measure the stitch density. During experimental work bobbin thread tension was kept constant and needle thread tension was measured by digital tension meter.

els using L9 orthogonal design. The ANOVA technique was carried out to see the effect of components on the seam quality. Sewn fabrics are tested for seam efficiency and seam strength on bursting strength testing machine on a model M229B hydraulic diaphragm bursting tester (SDL Atlas), was used in this study with ASTM D3786-01. $30 \pm 5 \mathrm{kPa}$ pressure required to lift diaphragm. Increasingly controlled hydrostatic pressure was applied to the underside of the diaphragm until the specimen bursts. Seam efficiency was measured by using following equation

\section{Method}

The distinctive effect of fabric types, stitch classes and thread types on seam quality were investigated in this study at three lev- 


\section{Results and Discussion}

\section{Study of seam strength}

Table 3 shows the effect of polyester/cotton core spun thread of different linear density on seam strength of lock stitch, chain stitch and over edge stitch for single jersey, rib \& interlock fabric. The results revealed from above Table 3 \& Figure 1 that all mentioned stitch types have highest seam strength in double jersey interlock weft knitted fabric compared to single jersey and rib fabric. Both stitch length and stitch density show negative influence on seam strength. As compared with single jersey and rib fabric, interlock fabric has less stitch length, more bursting strength and has high- est fabric density knitted with similar count. The stitch length is indirectly proportional to the seam strength. As the stitch length increases, the number of loops that shares the load decreases, resulting in decreasing seam strength. Sewing thread of linear density 80 Tex shows highest seam strength for over edge type of stitch in all fabrics as compared to 60 Tex and 40 Tex. This is attributed due to the fact that 80 Tex thread has more tenacity than 40 Tex and 60 Tex thread. These analyses agreed the common idea that double jersey fabrics are stronger than the single jersey fabric. Over edge type of stitch shows better seam strength compared to other stitch classes. This is because needle thread tension significantly influences on seam strength.

Table 3: Results of seam strength $(\mathrm{kPa}$

\begin{tabular}{|c|c|c|c|c|c|c|c|c|c|}
\hline \multicolumn{4}{|c|}{40 Tex Sewing Thread } & \multicolumn{3}{|c|}{60 Tex Sewing Thread } & \multicolumn{3}{|c|}{80 Tex Sewing Thread } \\
\hline Type of Stitch & $\begin{array}{l}\text { Single } \\
\text { Jersey }\end{array}$ & Rib & Interlock & $\begin{array}{l}\text { Single } \\
\text { Jersey }\end{array}$ & Rib & Interlock & $\begin{array}{l}\text { Single } \\
\text { Jersey }\end{array}$ & Rib & Interlock \\
\hline Lock stitch & 180.09 & 206.65 & 420.89 & 186.89 & 208.56 & 432.59 & 190.36 & 210.05 & 426.56 \\
\hline Chain stitch & 178.46 & 192.89 & 404.14 & 182.45 & 194.87 & 409.42 & 185.01 & 201.64 & 412.36 \\
\hline $\begin{array}{l}\text { Over edge } \\
\text { stitch }\end{array}$ & 182.78 & 212.00 & 430.00 & 188.26 & 212.89 & 435.26 & 192.36 & 222.17 & 430.45 \\
\hline
\end{tabular}
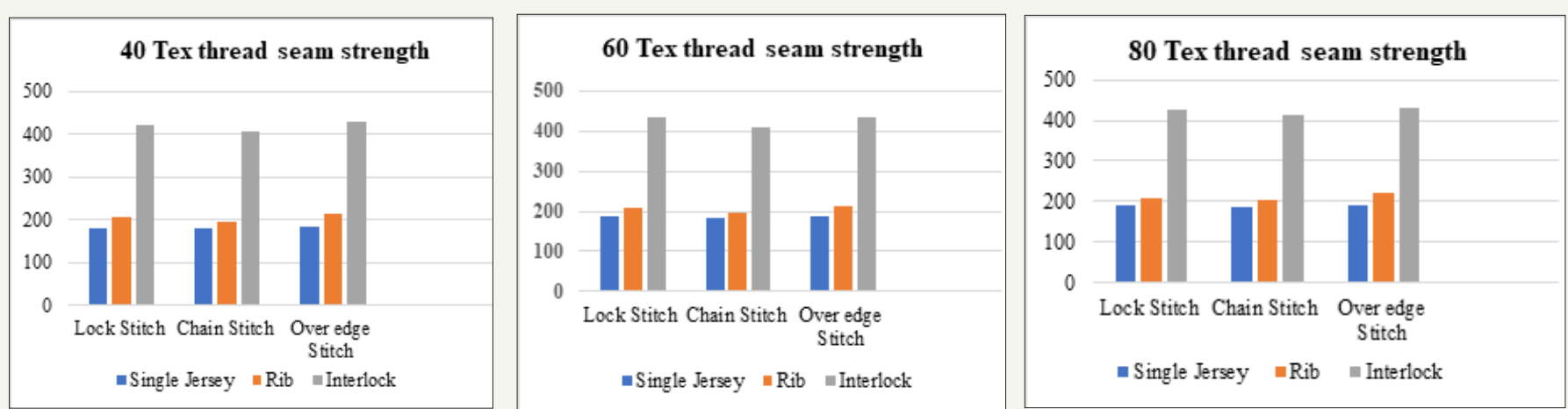

Figure 1: Effect of thread linear density on seam strength of lock stitch, chain stitch and over edge stitch for single jersey, rib $\&$ interlock fabric.

The results revealed from above Table 4 \& Figure 2 that all mentioned stitch types have highest seam efficiency in double jersey interlock weft knitted fabric compared to single jersey and rib fabric. Among all sewing thread 80 Tex thread shows higher seam efficiency. The linear density of sewing thread also shows considerably effect on seam efficiency. It is concluded that seam efficiency increases with increasing the linear density of sewing thread due to the more number of fibers is incorporated in the coarser sewing thread. It was also found that over edge type of stitch gives higher seam efficiency. This may be due to the fact that during stitching operation some flexibility at the seam occurs at low needle thread tension under sudden stress.

Table 4: Results of seam efficiency (\%).

\begin{tabular}{|c|c|c|c|c|c|c|c|c|c|}
\hline \multicolumn{4}{|c|}{ 40 Tex Sewing Thread } & \multicolumn{3}{c|}{60 Tex Sewing Thread } & \multicolumn{3}{c|}{ 80 Tex Sewing Thread } \\
\hline Type of Stitch & Single Jersey & Rib & Interlock & Single Jersey & Rib & Interlock & Single Jersey & Rib & Interlock \\
\hline Lock stitch & 74.32 & 82.56 & 92.82 & 77.13 & 83.32 & 95.41 & 78.56 & 83.91 & 94.08 \\
\hline Chain stitch & 73.65 & 77.06 & 89.13 & 75.29 & 77.85 & 90.29 & 76.35 & 80.55 & 90.94 \\
\hline Over edge stitch & 75.43 & 84.69 & 94.83 & 77.69 & 85.05 & 95.99 & 79.38 & 88.76 & 94.93 \\
\hline
\end{tabular}



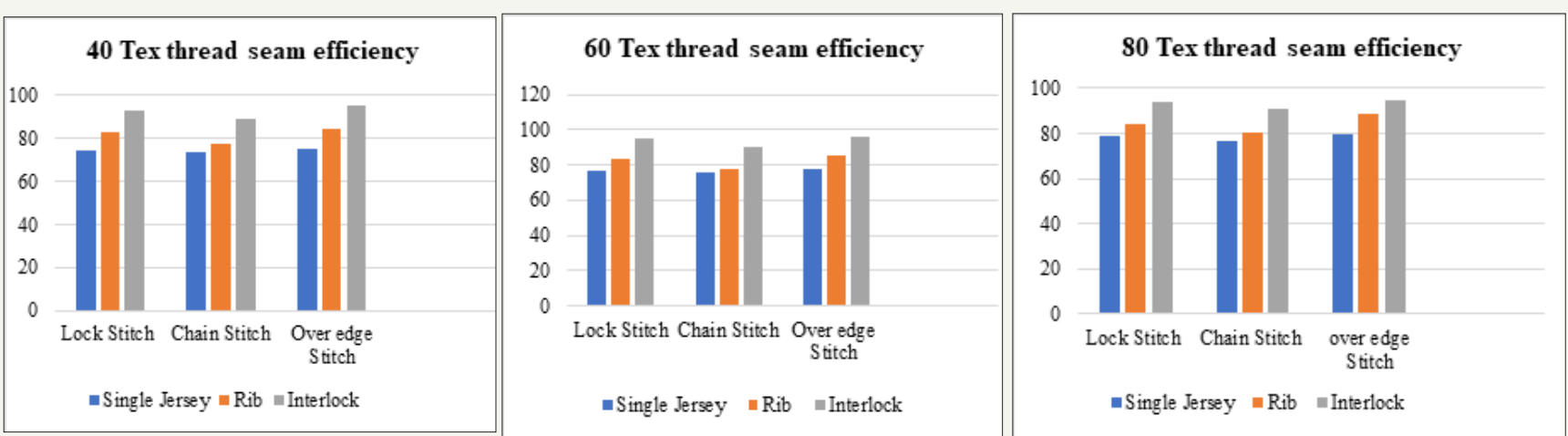

Figure 2: Effect of thread linear density on seam efficiency of lock stitch, chain stitch and over edge stitch for single jersey, rib $\&$ interlock fabric.

\section{Conclusion}

From the results it was concluded that different stitching threads will show different results on seam strength and seam efficiency. Types of fabric and their structural properties have significant effect on seam strength and seam efficiency. Higher strength of thread is prone for giving higher seam strength shows better functional performance of seam. Seam strength increases with the increase in sewing thread linear density. Interlock fabric seam strength is found more for all three stitch classes than other fabrics, particularly found more for over edge stitch. The statistical results revealed the effect of the stitch types, fabric types and sewing thread types on the seam strength and efficiency at significant level.

This present work had many circumstances that all seam classes could be selected instead of one and just three thread varieties could be selected. Based on the results of the study, it concluded that the work will be advantageous to investigate the sewing performance of any type of fabrics fit for various applications.

\section{References}

1. Behera BK, Sharma S (1998) Low-stress behavior and sewability of suiting and shirting fabrics. Indian Journal of Fiber and Textile Research 23(4): 233-241.

2. Ebrahim FFS (2012) Influence of mechanical properties of cotton fabrics on seam quality. Journal of American Science 8(5): 831-836.

3. Hu J, Chung S (2000) Bending behaviour of woven fabrics with vertical seams. Textile Research Journal 70(2): 148-153.

4. Gribaa S, Ben AS, Dogui A (2006) Influence of sewing parameters upon the tensile behavior of textile assembly. International journal of clothing science and Technology 18(4): 235-246.

5. Hui PC, Chan KC, Yeung KW, Ng FS (2007) Application of artificial neural networks to the prediction of sewing performance of fabrics.
International Journal of Clothing Science and Technology 19(5): 291318.

6. Yard SS (2005) Seam puckering in readymade garments. Textile Magazine 46(5): 86-87.

7. Dobilaite V, Juciene M (2006) The influence of mechanical properties of sewing threads on seam pucker. International Journal of Clothing Science and Technology 18(5): 335-345.

8. Ukponmwan JO, Mukhopadhyay A, Chatterjee KN (2000) Sewing threads. Textile progress 30(3/4): 1-91.

9. Giorgio Minazio P (1998) The fabric pressing performance and its role in predicting the appearance of men's wool suit jackets. International Journal of Clothing Science and Technology 10(3/4): 182-190.

10. Brain DH (1970) The prediction of strengths of lockstitch seams in woven fabrics. Journal of the Textile Institute 61(10): 493-505.

11. Mukhopadhyay A, Sikka M, Karmakar AK (2004) Impact of laundering on the seam tensile properties of suiting fabric. International Journal of Clothing Science and Technology 16(4): 394-403.

12. Rengasamy RS, Kothari VK, Alagirusamy R, Modi S (2003) Studies on airjet textured sewing threads. Indian Journal of Fiber and Textile Research 28(3): 281-287.

13. Ferreira FBN, Harlock SC, Grosberg P (1994) A study of thread tensions on a lockstitch sewing machine (part I). International Journal of Clothing Science and Technology 6(1): 14-19.

14. Meric B, Durmaz A (2005) Effect of thread structure and lubrication ratio on seam properties. Indian Journal of Fibre and Textile Research 30(3): 273-277.

15. Nayak R, Padhye R, Dhamija S, Kumar V (2013) Sewability of air-jet textured sewing threads in denim. Journal of Textile and Apparel Technology and Management 8(1): 1-11.

16. Padhye R, Nayak R (2010) Sewing performance of stretch denim. Journal of Textile and Apparel, Technology and Management 6(3): 1-9.

17. Pavlinic DZ, Gersak J, Demsar J, Bratko I (2006) Predicting seam appearance quality. Textile Research Journal 76(3): 235-242. 


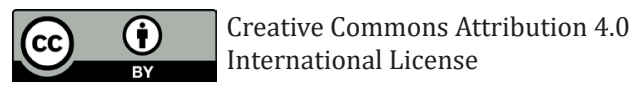

For possible submissions Click Here Submit Article
TTEFT

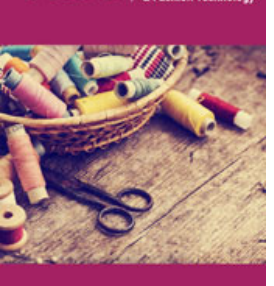

Trends in Textile Engineering \& Fashion Technology

\section{Benefits of Publishing with us}

- High-level peer review and editorial services

- Freely accessible online immediately upon publication

- Authors retain the copyright to their work

- Licensing it under a Creative Commons license

- Visibility through different online platforms 